\title{
An increase in perfusion pressure and activation of the renin-angiotensin system in the pathogenesis of hypertension and injury: strain vessels and the cerebrovascular-renal connection
}

\author{
Kouichi Tamura, Akinobu Maeda, Kazushi Uneda, Hiromichi Wakui, Toru Dejima, Hiroshi Mitsuhashi, \\ Satoshi Yamaguchi, Yuko Tsurumi-Ikeya, Yasuo Tokita and Satoshi Umemura
}

Hypertension Research (2012) 35, 972-974; doi:10.1038/hr.2012.108; published online 23 August 2012

\begin{abstract}
A ccumulating evidence indicates that A chronic kidney disease (CKD) is a major public health problem and a risk factor for all-cause mortality and cardiovascular disease. ${ }^{1}$ A previous large-scale epidemiological study, the Hisayama study, suggested that, in the Japanese population, CKD is one of the risk factors for ischemic heart disease but not necessarily for stroke. ${ }^{2}$ However, relatively recent results from other epidemiological studies showed that CKD is associated with a significantly increased risk of cerebral lacunar infarction and stroke, as well as ischemic heart disease, in the Japanese and other Asian populations. ${ }^{3-5}$ Thus, because the association between blood pressure (BP) and cerebrovascular and cardiovascular disease may be marked in patients with CKD, it is essential to strictly control the $\mathrm{BP}$, including the ambulatory BP profile, in patients with CKD, through lifestyle modification and proper clinical treatment, to prevent cerebrovascular and cardiovascular disease. ${ }^{6-8}$

Albuminuria and glomerular filtration rate are the key components of the assessment of the severity of CKD. These parameters are also closely associated with the ambulatory BP
\end{abstract}

K Tamura, A Maeda, K Uneda, H Wakui, T Dejima, $\mathrm{H}$ Mitsuhashi, Y Tsurumi-Ikeya and S Umemura are at the Department of Medical Science and Cardiorenal Medicine, Yokohama City University Graduate School of Medicine, Yokohama, Japan; S Yamaguchi is at the Department of Medicine, Division of Dialysis and Apheresis, Kohsaikai Kamio-oka Jinsei Clinic, Yokohama, Japan; Y Tokita is at the Department of Medicine, Renal Division, Fujisawa Municipal Hospital, Fujisawa, Japan

E-mail: tamukou@med.yokohama-cu.ac.jp profile, ${ }^{9}$ and they have prognostic significance for the development of cardiovascular disease (CVD). ${ }^{10,11}$ This strong association between ambulatory BP control and the renal function status, including albuminuria, deserves further discussion. Previous studies have reported strong correlations between the ambulatory $\mathrm{BP}$ level and albuminuria in hypertensive CKD patients. Albuminuria provoked by hypertension has been reported to result from podocyte injury with the subsequent loss of the glomerular filtration barrier. Mechanical forces related to renal perfusion pressure-induced increases in glomerular capillary pressure, such as shear stress and stretch, have been reported to alter the structure and function of podocytes, which can ultimately lead to an increase in the permeability of the glomerular filtration barrier to albumin. A previous study demonstrated that elevated renal perfusion pressure is directly responsible for the excess albuminuria in Ang II-induced hypertensive rats, whereas both elevated renal perfusion pressure and Ang II directly contribute to the observed renal oxidative stress, suggesting that it is mainly the BP lowering itself that is the most important factor in normalizing albuminuria in Ang IIinduced hypertensive rats. ${ }^{12}$

In relation to the direct pathological action of elevated renal perfusion pressure, a series of studies by Ito's laboratory showed that the anatomical characteristics of pre-glomerular vessels and cerebrovascular small vessels, such as perforating arteries, underlie the pathophysiological basis of the association between CKD and cerebrovascular disease. ${ }^{13}$ These small vessels branch directly from larger arteries and are directly exposed to high BP to maintain a large pressure gradient over a short distance; thus, they are named 'strain vessels. ${ }^{13}$

In the current issue of Hypertension Research, in line with the hypothesis of Ito's laboratory that microalbuminuria is a marker of cerebrovascular-renal injury, Nagasawa et al. ${ }^{14}$ from Ito's laboratory, studied strokeprone spontaneously hypertensive rats (SHR-SP) rats fed a high-salt diet and showed interesting relationships between pre-glomerular vessel lesions of the juxtamedullary nephron and the development of albuminuria and vessel lesions of the cerebral perforating artery. In addition, they demonstrated that nifedipinemediated BP lowering reduced the albuminuria with a concomitant improvement in the juxtamedullary nephron injury, as well as stroke events in these hypertensive rats. The authors thereby concluded that the albuminuria was a result of the juxtamedullary nephron injury and a marker of pressure-induced injury of the strain vessels.

Ang II-dependent renal injury has mostly been observed in the outer-cortical glomeruli, and BP-dependent renal injury has mostly been observed in the juxtamedullary glomeruli. ${ }^{15}$ However, previous studies have also reported that the renal medullary circulation has a fundamental role in regulating long-term BP control and fluid balance and that the Ang II-mediated intrarenal elevation of superoxide levels and Ang II-mediated reduction in NO levels in the renal medulla decreases medullary blood 


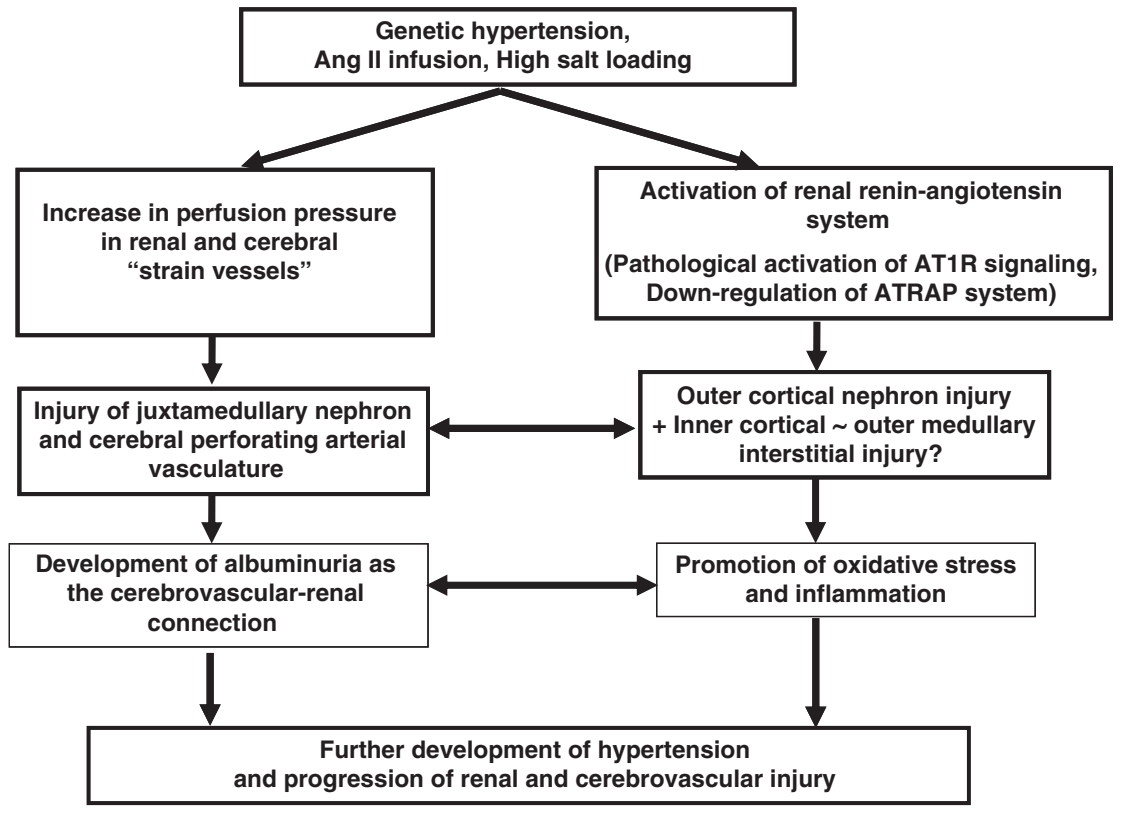

Figure 1 Schema showing the proposed roles of the cerebrovascular-renal connection via 'strain vessels' and the activation of the renal renin-angiotensin system in the development of hypertension and its related cerebrovascular and renal injuries.

flow and $\mathrm{Na}^{+}$excretion, resulting in sustained hypertension. ${ }^{16}$ Thus, inhibitors of the renin-angiotensin system such as Ang II receptor blockers are also expected to exert beneficial effects on juxtamedullary nephron injury and albuminuria in SHR-SP rats, although Nagasawa et al. ${ }^{14}$ did not compare the therapeutic effects of nifedipine with those of renin-angiotensin system inhibitors such as Ang II receptor blockers in SHR-SP rats.

The Ang II type 1 receptor-associated protein (ATRAP), which specifically interacts with the carboxyl-terminal domain of Ang II type 1 receptor, was cloned using a yeast-two hybrid screening system. ${ }^{17,18}$ The results of previous in vitro studies and ATRAPtransgenic mouse studies have shown that ATRAP suppresses Ang II-mediated pathological responses in cardiovascular cells and tissues by promoting the constitutive internalization of Ang II type 1 receptor, thereby suggesting that ATRAP is an endogenous inhibitor of Ang II type 1 receptor signaling. Our previous studies also revealed that there was significant suppression of endogenous ATRAP expression in the renal inner cortex and outer medulla concomitant with the development of Ang II-mediated hypertension and salt-sensitive hypertension. ${ }^{19,20}$ A previous study showed that as SHR-SP rats developed hypertension, the genes encoding components of the renin- angiotensin system were expressed at higher levels in the kidney ${ }^{21}$; therefore, it was proposed that the intrarenal reninangiotensin system is activated by this type of genetic hypertension. Thus, further investigations are warranted to examine the possible role of renal ATRAP in the pathophysiology of hypertension and renal injury, including albuminuria and the production of oxidative stress-related molecules, in SHR-SP rats (Figure 1).

1 Matsushita K, van der Velde M, Astor BC, Woodward M, Levey AS, de Jong PE, Coresh J, Gansevoort RT. Association of estimated glomerular filtration rate and albuminuria with all-cause and cardiovascular mortality in general population cohorts: a collaborative metaanalysis. Lancet 2010; 375: 2073-2081.

2 Ninomiya T, Kiyohara Y, Kubo M, Tanizaki Y, Doi Y, Okubo K, Wakugawa Y, Hata J, Oishi Y, Shikata K, Yonemoto K, Hirakata H, lida M. Chronic kidney disease and cardiovascular disease in a general japanese population: the hisayama study. Kidney Int 2005; 68: 228-236.

3 Kokubo Y, Nakamura S, Okamura T, Yoshimasa Y, Makino $\mathrm{H}$, Watanabe $\mathrm{M}$, Higashiyama A, Kamide $\mathrm{K}$, Kawanishi K, Okayama A, Kawano Y. Relationship between blood pressure category and incidence of stroke and myocardial infarction in an urban japanese population with and without chronic kidney disease: the suita study. Stroke 2009; 40: 2674-2679.

4 Ohishi M, Tatara Y, Ito N, Takeya Y, Onishi M, Maekawa $\mathrm{Y}$, Kato N, Kamide K, Rakugi $\mathrm{H}$. The combination of chronic kidney disease and increased arterial stiffness is a predictor for stroke and cardiovascular disease in hypertensive patients. Hypertension Res 2011; 34. 1209-1215
5 Shima H, Ishimura E, Naganuma T, Ichii M, Yamasaki T, Mori K, Nakatani T, Inaba M. Decreased kidney function is a significant factor associated with silent cerebral infarction and periventricular hyperintensities. Kidney Blood Press Res 2011; 34: 430-438.

6 Ozawa M, Tamura K, Okano Y, Matsushita K, Ikeya Y, Masuda S, Wakui H, Dejima T, Shigenaga A, Azuma K, Ishigami T, Toya $\mathrm{Y}$, Ishikawa T, Umemura S. Blood pressure variability as well as blood pressure level is important for left ventricular hypertrophy and brachialankle pulse wave velocity in hypertensives. Clin Exp Hypertens 2009; 31: 669-679.

7 Tamura K, Kanaoka T, Ohsawa M, Haku S, Azushima K, Maeda A, Dejima T, Wakui H, Ozawa M, Shigenaga A, Toya Y, Umemura S. Emerging concept of anti-hypertensive therapy based on ambulatory blood pressure profile in chronic kidney disease. Am J Cardiovasc Dis 2011; 1: 236-243.

8 Yamamoto $Y$, Ohara $T$, Nagakane $Y$, Tanaka $E$, Morii $F$, Koizumi T, Akiguchi I. Chronic kidney disease, 24-h blood pressure and small vessel diseases are independently associated with cognitive impairment in lacunar infarct patients. Hypertension Res 2011; 34: 1276-1282.

9 Kanaoka T, Tamura K, Ohsawa M, Yanagi M, Haku S, Wakui H, Maeda A, Dejima T, Azushima K, Mitsuhashi $\mathrm{H}$, Okano $\mathrm{Y}$, Fujikawa T, Toya $\mathrm{Y}$, Mizushima S, Tochikubo O, Umemura S. Relationship of ambulatory blood pressure and the heart rate profile with renal function parameters in hypertensive patients with chronic kidney disease. Clin Exp Hypertens 2012; 34: 264-269.

10 Solini A, Penno G, Bonora E, Fondelli C, Orsi E, Arosio $M$, Trevisan R, Vedovato M, Cignarelli M, Andreozzi F, Nicolucci A, Pugliese G. Diverging association of reduced glomerular filtration rate and albuminuria with coronary and noncoronary events in patients with type 2 diabetes: The renal insufficiency and cardiovascular events (riace) italian multicenter study. Diabetes Care 2012; 35: 143-149.

11 Yokoyama H, Araki S, Haneda M, Matsushima M, Kawai K, Hirao K, Oishi M, Sugimoto K, Sone H, Maegawa $H$, Kashiwagi A. Chronic kidney disease categories and renal-cardiovascular outcomes in type 2 diabetes without prevalent cardiovascular disease: a prospective cohort study (jddm25). Diabetologia 2012; 55: 1911-1918.

12 Polichnowski AJ, Jin C, Yang C, Cowley Jr AW. Role of renal perfusion pressure versus angiotensin ii on renal oxidative stress in angiotensin ii-induced hypertensive rats. Hypertension 2010; 55: 1425-1430.

13 Ito S, Nagasawa T, Abe M, Mori T. Strain vessel hypothesis: a viewpoint for linkage of albuminuria and cerebro-cardiovascular risk. Hypertension Res 2009; 32: 115-121.

14 Nagasawa T, Mori T, Ohsaki Y, Yoneki Y, Guo Q, Sato E, Oba I, Ito S. Albuminuria indicates the pressureassociated injury of juxtamedullary nephrons and cerebral strain vessels in spontaneously hypertensive stroke-prone rats. Hypertens Res 2012; 35: 1024 1031.

15 Mori T, Cowley Jr AW. Role of pressure in angiotensin iiinduced renal injury: chronic servo-control of renal perfusion pressure in rats. Hypertension 2004; 43: 752-759.

16 Mori T, Cowley Jr AW, Ito S. Molecular mechanisms and therapeutic strategies of chronic renal injury: physiological role of angiotensin ii-induced oxidative stress in renal medulla. J Pharmacol Sci 2006; 100: $2-8$

17 Mogi M, Iwai M, Horiuchi M. Emerging concepts of regulation of angiotensin ii receptors: new players and targets for traditional receptors. Arterioscler Thromb Vasc Biol 2007; 27: 2532-2539.

18 Tamura K, Tanaka Y, Tsurumi Y, Azuma K, Shigenaga A, Wakui H, Masuda S, Matsuda M. The role of angiotensin at 1 receptor-associated protein in renin-angiotensin system regulation and function. Curr Hypertens Rep 2007; 9: 121-127.

19 Wakui H, Tamura K, Matsuda M, Bai Y, Dejima T, Shigenaga A, Masuda S, Azuma K, Maeda A, Hirose T, Ishigami T, Toya Y, Yabana M, Minamisawa S, 
Umemura S. Intrarenal suppression of angiotensin i type 1 receptor binding molecule in angiotensin ii-infused mice. Am J Physiol Renal Physiol 2010; 299: F991-F1003.

20 Dejima T, Tamura K, Wakui H, Maeda A, Ohsawa M, Kanaoka T, Haku S, Kengo A, Masuda S, Shigenaga A,
Azuma K, Matsuda M, Yabana M, Hirose T, Uchino K, Kimura K, Nagashima Y, Umemura S. Prepuberta angiotensin blockade exerts long-term therapeutic effect through sustained atrap activation in saltsensitive hypertensive rats. J hypertens 2011; 29 1919-1929.
21 Obata J, Nakamura T, Takano H, Naito A, Kimura H, Yoshida Y, Shimizu F, Guo D-F, Inagami $T$, Increased gene expression of components of the renin-angiotensin system in glomeruli of genetically hypertensive rats. J Hypertens 2000; 18 1247-1255. 